\title{
Analysis of the target group of lactose-free functional foods for product development
}

\author{
E. Szabó, D. Szakos, Gy. Kasza and L. Ózsvári* ๑)
}

Department of Veterinary Forensics and Economics, University of Veterinary Medicine Budapest, H1078 Budapest, István út 2, Hungary

\section{ORIGINAL RESEARCH PAPER}

Received: June 17, 2020 • Accepted: February 8, 2021

Published online: April 2, 2021

(C) 2021 The Author(s)

\begin{abstract}
The aim of this research was to assess the consumer habits of lactose sensitive persons in case of lactose-free products and their other shopping aspects for development of new, dairy-based lactose-free products. The research was based on face-to-face questionnaire survey, and those who declared to be lactose sensitive were analysed. Among them, only half of the women (49.3\%) and one third of the men (34.6\%) were medically proven lactose sensitive, so more than half of the respondents declared themselves affected on the basis of self-diagnosis. Our results show that reliably regular customers of lactose-free products are women and persons with medical diagnosis, high educational degree, and under the age of 30 . The lactose-free consumer group prefers the following product features: lactose-free label; rich in calcium, vitamins, and fibre, and free of carbohydrate, sugar, and gluten. Only two-thirds of lactose sensitive customers (66.7\%) consume lactose-free products regularly, so it can be assumed that the level of knowledge of this disease, its treatment, and the importance of lactose-free dairy products among these persons is insufficient. This could be solved with education, advertisement, and other information opportunities.
\end{abstract}

\section{KEYWORDS}

nutrition science, lactose sensitivity, consumer habits, lactose-free product

*Corresponding author. Tel.: +36 1478 4185. E-mail: ozsvari.laszlo@univet.hu 


\section{INTRODUCTION}

The concept of functional food has been defined countless times, which differs from country to country (Stanton et al., 2001; Siro et al., 2008; Bigliardi and Galati, 2013). Those foodstuffs can be considered functional food in the European Union, which have a positive physiological impact due to their nutrient composition (Ovesen, 1997; Verhagen et al., 2010), such as lactosefree foodstuffs. In terms of the opportunities for functional products to enter the domestic market, it is important to have competitive advantages in the agricultural and food industries, so that they can play an effective role in the development of functional foods (Szakály et al., 2012; Kiss et al., 2019; Szakos et al., 2020).

In the body of a lactose sensitive person, the lactase enzyme produced in the small intestine is innately absent or impaired (primary lactose sensitivity), or it is an intestinal problem due to antibiotic treatment (secondary lactose intolerance), which results in acute abdominal symptoms following the consumption of milk (Swallow, 2003; Lomer et al., 2007). Lactose sensitivity is present in two-thirds of the world's population (Storhaug et al., 2017). Lactose sensitivity can be proven by hydrogen breath test, lactose provocation test, and genetic testing (Lomer et al., 2007). Lactose sensitivity can be treated by low or lactose-free diet, lactase enzyme replacement (Gasztonyi et al., 2018), or with the treatment of the underlying disease in the case of secondary lactose sensitivity (Gerbault et al., 2014).

Among doctors, it is a well-known phenomenon that many persons diagnose themselves with the disease without a doctor confirming it, which can be dangerous, because other diseases could remain undiagnosed (Hodges et al., 2019). It is important to emphasise that different gastrointestinal symptoms can be considered outstandingly frequent in our society, and most affected persons believe that the main cause of the symptoms is milk or dairy products. It can become a public health issue if too many persons diagnose themselves lactose sensitive, even though the symptoms of most of them are not related to lactose sensitivity (Csíki et al., 2011).

The aim of this research was to assess the consumer habits of lactose sensitive persons in case of lactose-free products and their other shopping aspects for development of new, dairy-based lactose-free products.

\section{MATERIALS AND METHODS}

Research methodology was a quantitative survey with 1,002 respondents. The sample was representative based on the 2016 microcensus of the Hungarian Central Statistical Office by age, sex, and location of habitat based on Nomenclature of Territorial Units for Statistics (NUTS) regions (Hungarian Central Statistical Office, 2017). Most of the questions were close-ended, and 5-point Likert scale was applied. The survey took place in both larger cities and smaller towns from all over the country between July and August 2018. In the beginning of the interview, the respondents were informed about the aim of the research and the management of anonymous data. If the respondents were willing to participate, the quota parameters (age, sex, geographical location) had been recorded before the research questions were asked, allowing the quota numbers to be tracked by the interviewers to ensure an appropriate level of representability. Each questionnaire has been coded to detect inaccuracies in data entry. The data were edited in MS Excel (Microsoft Corporation, Redmond, WA, USA), and the error-filtered data 
Table 1. Socio-demographic data of analysed samples (\%)

\begin{tabular}{lcc}
\hline & $(n=1,002)$ & Lactose sensitive group $(n=99)$ \\
\hline Sex & & \\
$\quad$ Female & 53.19 & 70.70 \\
$\quad$ Male & 46.81 & 29.30 \\
Age & 17.96 & \\
$\quad$ Under 30 & 16.97 & 18.37 \\
30-39 & 34.53 & 14.29 \\
40-59 & 30.54 & 29.59 \\
Over 60 & & 37.76 \\
Location of habitat & 15.60 & \\
$\quad$ Village & 61.40 & 17.53 \\
City & 23.00 & 52.58 \\
$\quad$ Capital & & 29.90 \\
Education & 11.50 & 1.03 \\
$\quad$ Less than high school & 33.30 & 39.17 \\
High school & 55.20 & 59.79 \\
Higher education & & \\
Income level & 0.80 & 1.02 \\
$\quad$ Low & 12.40 & 14.29 \\
Below average & 68.00 & 71.43 \\
Average & 17.10 & 10.20 \\
Above average & 1.70 & 3.06 \\
Outstanding & & \\
\hline
\end{tabular}

were statistically analysed in R version 3.6.1. using T-test (De Winter and Dodou, 2010; Boone and Boone, 2012; R Core Team, 2020). The level of significance was set to 0.05 .

As a first step of processing data, the aim was to find the expected target group of a new lactose-free product, so persons affected by lactose sensitivity were selected based on the question "Are you, or anyone in your family affected by lactose sensitivity?".

The results showed that $10.4 \%$ of the respondents were lactose sensitive. Following this, selfreported lactose sensitive respondents were analysed as a lactose sensitive group.

Socio-demographic characteristics of lactose sensitive respondents were compared to the characteristics of the whole sample (Table 1).

\section{RESULTS AND DISCUSSION}

\subsection{Consumer habits of lactose sensitive group regarding lactose-free foodstuffs}

In the analysed lactose sensitive group, half of female respondents (49.3\%) and a third of male respondents $(34.6 \%)$ visited a doctor because of lactose sensitivity, the others claimed to be lactose sensitive based on self-diagnosis. In the framework of this research, the frequency of the consumption of lactose-free dairy products within the lactose sensitive group was also analysed. Surprisingly, a significant proportion of the group (19.8\%) almost never consumes such products (Likert 1-2), which can be attributed to the full abandonment of milk and dairy 
product consumption. It is well-reported in the literature that in many cases, the complete abandonment of milk and dairy products characterises the diet of patients suffering from lactose indigestion, even though the development of lactose-free dairy products is becoming increasingly widespread, ranging from yoghurt to lactose-reduced milk powders (Varga et al., 2004; Morioka et al., 2018). It is also known that the complete abandonment of dairy products could lead to calcium, vitamin D, and protein deficiency (Gasztonyi et al., 2018; Hodges et al., 2019). The percentage of those respondents who reported that they regularly consume lactose-free products (Likert 4-5) was 66.7\%. Significant correlation was detected between the real existence of lactose sensitivity (both medical and self-diagnosis) and the frequency of consumption $(P=$ 0.0246) (Fig. 1).

The correlation between sex and frequency of consumption was significant $(P<0.05): 71.0 \%$ of female respondents while only $55.5 \%$ of male respondents consume lactose-free products regularly. Considering age groups, it was found that an exceptionally high percentage of respondents $(88.9 \%)$ under the age of 30 consume lactose-free dairy products regularly, while other age groups have a smaller share of regular consumers (50.0-63.0\%) and higher share of non-consumers (17.0-28.0\%). Regarding the education level, the ratio of non-consumers having higher education was outstanding (15.5\%), while the number of regular consumers of lactosefree dairy products was the highest for respondents with high school degree $(60.0 \%)$, which does not support international findings, saying that consumers of higher-priced functional foods often belong to groups with higher education (De Jong et al., 2004).

In terms of level of income, significant proportions of lactose sensitive respondents have below average (14.3\%), average (71.4\%), and above average (10.2\%) income, and their purchase frequency does not change significantly with increasing income levels $(P=0.4204)$. Furthermore, while comparing respondents from different locations of residence, it was found that there is no significant difference in the frequency of consumption of lactose-free products among those living in a village, city, or the capital $(P=0.7745)$. We assumed that purchase can also be influenced by the family member who is responsible for food buying, but no significant correlation was found between this factor and the frequency of consumption of lactose-free products. However, the correlation was significant in the case of sex $(P<0.001) ; 52.2 \%$ of women reported that they do the shopping themselves, $46.4 \%$ reported that they share it, while for male respondents these shares were 18.0 and $64.3 \%$, respectively.

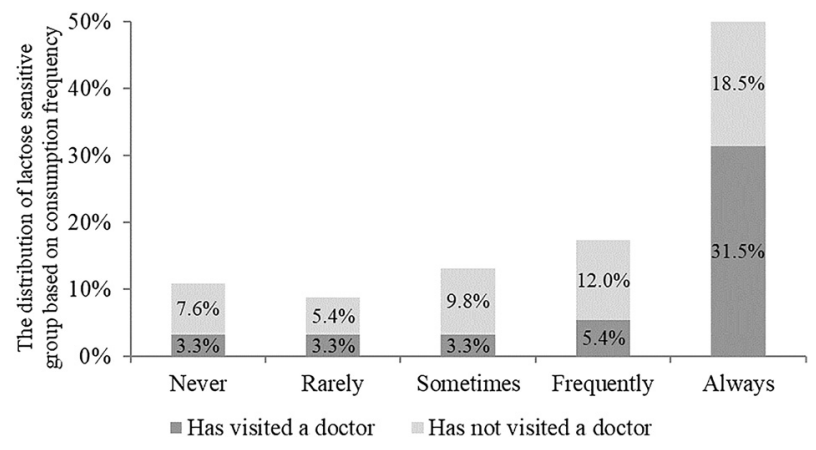

Fig. 1. The correlation between the consumption frequency of lactose-free products and the existence of medical diagnosis in the lactose sensitive group 
To reveal the reason behind frequency of consumption, it was analysed how worried/affected the lactose sensitive respondents were by their disease and if they would be willing to undertake additional expenses to prevent the problem. The results showed that $8.1 \%$ of the lactose sensitive consumers were not worried/affected at all, 16.1\% were worried/affected but would not pay to avoid it, and $75.9 \%$ were worried/affected and would pay to avoid it. These findings were compared to the consumption frequency of lactose-free products in this group (Fig. 2), and it was found that the consumption frequency was significantly correlated to being affected by lactose sensitivity and the willingness to pay $(P<0.001)$. Although they reported to be lactose sensitive, $8.1 \%$ of this group were not worried/affected by the disease, and this proportion was close to the share of those lactose sensitive persons who never consumed lactose-free products (11.5\%). Moreover, there was a significant correlation between sex and concerns about lactose sensitivity $(P<0.05) ; 83.9 \%$ of the female consumers responded that "I am affected, and I am willing to pay for it," while only $56.0 \%$ of the male respondents did so.

Albeit there was no significant correlation between the age groups and the consumers who were worried about the disease $(P=0.8779)$, greater difference was found in the group from 30 to 40 years of age. $23.0 \%$ of this group responded that "I am affected, but I wouldn't pay for it", and $69.7 \%$ of them do not consume or just rarely consume lactose-free products.

For the question "Is there any reason why you need special diet?", $12.4 \%$ of lactose sensitive respondents chose the answer "There is no reason," which is close to the $11.5 \%$ share of those who do not consume lactose-free products (Fig. 2) and those who are not worried/affected by lactose sensitivity (9.0\%).

When the lactose sensitive group was asked about the importance of lactose-free labelling, the distribution of answers for the question "When purchasing food, how much do you prefer a product to have lactose-free labelling?" were the following: 5.2\% not preferred, $4.1 \%$ maybe preferred, $15.5 \%$ a little preferred, $17.5 \%$ preferred, and $57.7 \%$ very preferred.

Analysing the whole sample, significant correlation was found between the lactose sensitivity and $(1)$ the worry about the disease and willingness to pay $(P<0.001)$ and $(2)$ the importance of

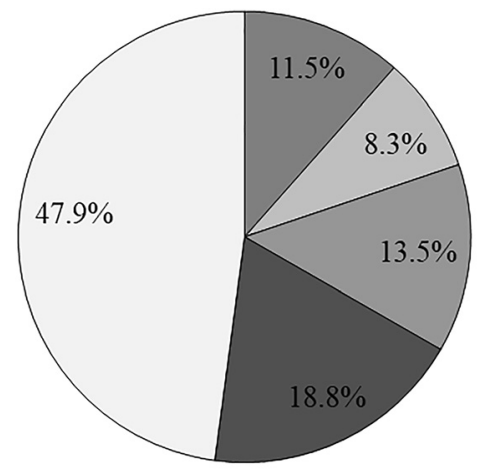

$\square$ Never $\square$ Rarely $\square$ Sometimes $\square$ Frequently $\square$ Always

Fig. 2. Distribution of consumption frequency of lactose-free products in the lactose sensitive group 
lactose-free labelling $(P<0.001)$, furthermore, between the consumption frequency of lactosefree products and the importance of lactose-free labelling $(P<0.001)$.

Therefore, it can be stated that $66.7 \%$ of those who are personally affected by lactose sensitivity can be considered the target group of lactose-free products, since they (1) are really affected by this problem and willing to pay more for them, (2) regularly consume these products, and (3) consider lactose sensitive labelling also important. Meanwhile, for $33.3 \%$ of lactose sensitive respondents none of these factors is important and presumably, they simply exclude milk and dairy products from their diet, which they do not consider a special diet.

Lactose sensitive persons are prone to leave out the main source of calcium, dairy products, due to unpleasant gastro-intestinal symptoms, therefore, dietary counselling should emphasize that the consumption of lactose-free dairy products could cover the need for calcium, and the complete abandonment of dairy products could lead to deficiencies (Gasztonyi et al., 2018).

Sixty-nine percent of the lactose sensitive respondents considered the calcium content labelling to be important while shopping, but this product characteristic was also important for $65.0 \%$ of the not lactose sensitive consumers, as well. The difference is minimal, so lactose sensitive persons do not pay more attention to calcium intake than an average consumer.

\subsection{Attitudes of the lactose sensitive group towards their lactose sensitivity}

The collected data were also analysed to examine how the lactose sensitive persons treat their health condition, based on their responses given to the question "If the problems you identified could be treated/prevented in several ways, which of the following options would you prefer?" (Fig. 3). It must be noted that professionally, the term "healthy food" instead of "functional food" is not correct, since there are safe foods and healthy diet, which means knowing and providing our body with the right proportions of nutritionally necessary substances. Although, the term "healthy food" was used in the questionnaire, since this term is more widely used by consumers and could have been replaced only in a complicated way in the text of the questionnaire.

No difference was found in the order of importance between those that visited a doctor and those who self-diagnosed themselves as lactose sensitive, and their consumption frequency did not differ either. The order of importance for the lactose sensitive group was in accordance with the order for the not lactose sensitive respondents $(P=0.2064)$, so there was no difference in the opinions on lactose sensitivity between the medically affected and not affected respondents. That is, the whole sample primarily chose functional food as the treatment of lactose sensitivity.

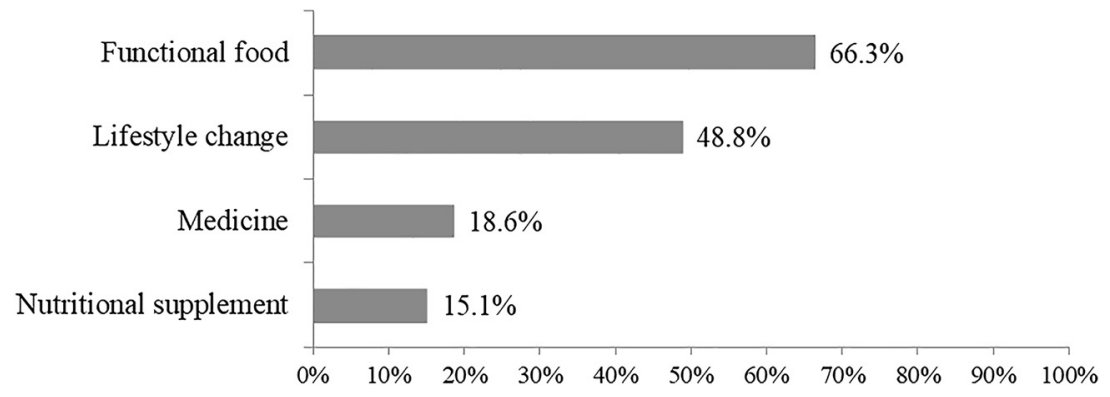

Fig. 3. The order of importance of the methods to treat/prevent lactose sensitivity in the lactose sensitive group 


\subsection{Preference for other product characteristics in the lactose sensitive group}

In terms of the development of a new product, the demand for other attributes associated with the base product is important, thus, we examined which product characteristics are preferred by the lactose sensitive group. Our survey results showed that, apart from the lactose sensitive label, the most preferred product labels by the customers are the following: rich in vitamins, calcium, fibre, and whole grain. While for an average customer gluten-free (2.3) and lactose-free (2.4) labels are of less importance, both the lactose-free (4.2) and gluten-free (3.1) labels are more prioritised by the lactose sensitive group. Therefore, lactose-free dairy products with other characteristics such as rich in calcium, vitamins, and fibre, and gluten-free would be expected to be positively received. Furthermore, $38.0 \%$ of lactose sensitive respondents consume carbohydrate-free products and $40.0 \%$ sugar-free products, while these rates for the not lactose sensitive respondents are approximately 10.0 percentage point less each.

\subsection{Differences in the consumption frequency in the lactose sensitive group}

Within the lactose sensitive group, two subgroups were also compared: those who frequently (Likert 4) and those who always (Likert 5) consume lactose-free products. The rate of medicallyproven lactose sensitive persons was higher among those who always consume lactose-free foodstuff, while for those who frequently consume, the rate of self-diagnosed lactose sensitivity was higher, which assumes an irregular consumer base, since it is not certain that they have any issues with lactose. Between the two subgroups significant differences were found regarding their worry about lactose sensitivity and their willingness to pay to avoid it $(P<0.05)$ and the importance of lactose-free labelling $(P<0.001)$ (Fig. 4).

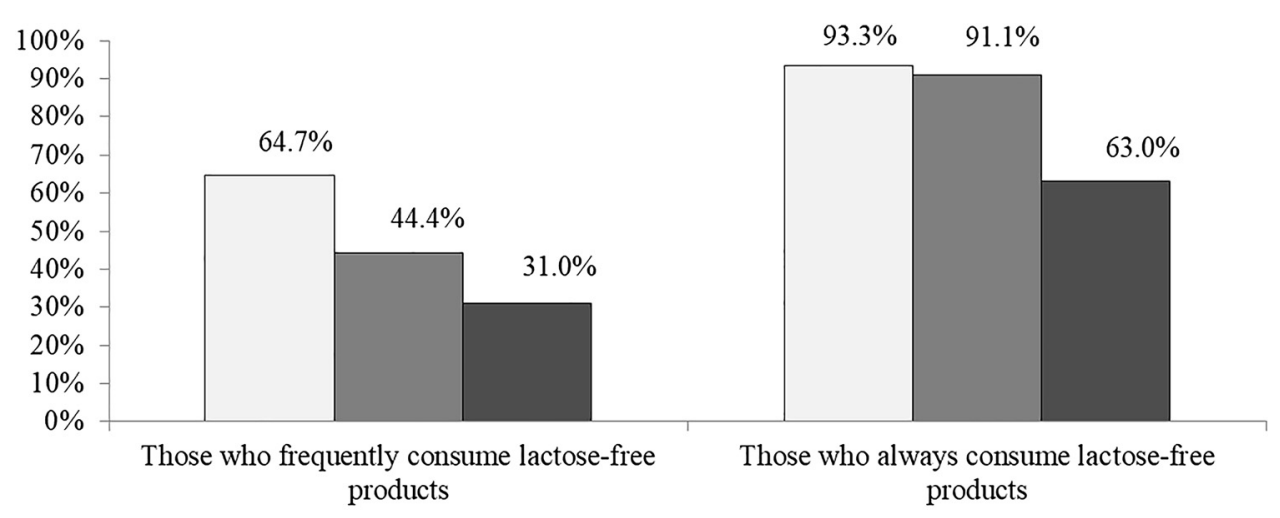

$\square$ Affected by lactose sensitivity, and would pay to avoid it

$\square$ Lactose-free labelling is very advantageous

$\square$ Has a medical diagnosis

Fig. 4. Differences between lactose sensitive persons who always or frequently consume lactose-free products 
Significant difference was also found between the subgroups regarding the treatment of lactose sensitivity. In the subgroup, where the respondents always consume lactose-free products, lactose sensitive persons chose lifestyle change $(53.3 \%)$ and healthy food (55.6\%) as possible ways of treating lactose sensitivity in equal proportions. On the contrary, in the subgroup of those who frequently consume such products, the most preferred way was healthy food (87.5\%), while lifestyle change was less important (37.5\%), which might indicate that they have less correct information about the disease than the other subgroup.

\section{CONCLUSIONS}

Our findings show that women pay more attention to their health and are willing to pay more to stay healthy, so they are more reliable customers of lactose-free products. This is due in part to the fact that more than half of the surveyed women do the shopping themselves, while most men prefer shopping together with other family members, therefore, women can be considered decision makers in food purchasing. More than half of the lactose sensitive persons declared themselves affected by self-diagnosis, thus, lack of medical diagnosis can also largely affect customer habits, therefore, emphasising the importance of medical examination would be essential.

Two-thirds of the lactose sensitive persons considered the consumption of functional food products as the primary treatment for lactose sensitivity. Contrary to this, only two-thirds of them consume lactose-free products regularly, so it can be assumed that lactose sensitive persons are not fully aware of the disease and its treatment options, and the importance of lactose-free dairy products. These findings revealed information gaps that could be addressed by conducting awareness campaign targeting both children and adults through education and public catering.

\section{ACKNOWLEDGEMENT}

The Project was supported by the European Union and co-financed by the European Social Fund: (1) EFOP-3.6.1-16-2016-00024 'Innovations for Intelligent Specialisation on the University of Veterinary Science and the Faculty of Agricultural and Food Sciences of the Széchenyi István University Cooperation' and (2) EFOP-3.6.3-VEKOP-16-2017-00005 'Strengthening the scientific replacement by supporting the academic workshops and programs of students, developing a mentoring process'.

\section{REFERENCES}

Bigliardi, B. and Galati, F. (2013). Innovation trends in the food industry: the case of functional foods. Trends in Food Science \& Technology, 31(2): 118-129.

Boone, H.N., and Boone, D.A. (2012). Analyzing Likert data. Journal of Extension, 50(2): 1-5.

Csíki, Z., Kovács, D., Csíki, E., András, Cs., Papp, G., and Paragh, Gy. (2011). A laktózérzékenység gyakorlati vonatkozásai (Practical aspects of lactose sensitivity). Metabolizmus, 9(3): 180-183. 
De Jong, N., Simojoki, M., Laatikainen, T., Tapanainen, H., Valsta, L., Lahti-Koski, M., Uutela, A., and Vartiainen, E. (2004). The combined use of cholesterol-lowering drugs and cholesterol lowering bread spreads: health behaviour data from Finland. Preventive Medicine, 39: 849-855.

De Winter, J.F.C. and Dodou, D. (2010). Five-point Likert items: t test versus Mann-Whitney-Wilcoxon. Practical Assessment, Research, and Evaluation, 15(1): 11-16.

Gasztonyi, B., Bajor, J., Tihanyi, M., and Herszényi, L. (2018). A laktózintolerancia gyakorlati megközelítése. (Current clinical approach of lactose intolarence). Central European Journal of Gastroenterology and Hepatology, 4(1): 217-222. (In Hungarian, with English abstract).

Gerbault, P., Liebert, A., Swallow, D.M., and Thomas, M.G. (2014). Lactose malabsorption and nutrition In: Lomer, M. (Ed.), Advanced nutrition and dietetics in gastroenterology. Wiley-Blackwell, UK, pp. 202-209.

Hodges, J.K., Cao, S., Cladis, D.P., Weaver, C.M. (2019). Lactose intolerance and bone health: the challenge of ensuring adequate calcium intake nutrients. Nutrients, 11(4): 1-17.

Hungarian Central Statistical Office (2017). Microcensus 2016. Available at: https://www.ksh.hu/ mikrocenzus2016/?lang=en.

Kiss, A., Popp, J., Oláh, J., and Lakner, Z. (2019). The reform of school catering in Hungary: anatomy of a health-education attempt. Nutrients, 11(4): 716. https://doi.org/10.3390/nu11040716.

Lomer, M.C.E., Parkes, G.C., and Sanderson, J.D., (2007): Review article: lactose intolerance in clinical practice -myths and realities. Alimentary Pharmacology \& Therapeutics, 27: 93-103.

Morioka, L.R.I, Koga, E.C., and Suguimoto, H.H. (2018). Development and evaluation of freeze-dried milk powder with low-lactose content. Acta Alimentaria, 47: 283-290.

Ovesen, L. (1997). Regulatory aspects of functional foods. European Journal of Cancer Prevention: The Official Journal of the European Cancer Prevention Organisation (ECP), 6(5): 480-482.

R Core Team (2020). R: a language and environment for statistical computing. R Foundation for Statistical Computing, Vienna, Austria. Available at: http://www.R-project.org/.

Siro, I., Kápolna, E., Kápolna, B., and Lugasi, A. (2008). Functional food. Product development, marketing and consumer acceptance. A review. Appetite, 51(3): 456-467.

Stanton, C., Gardiner, G., Meehan, H., Collins, K., Fitzgerald, G., Lynch, P.B., and Ross, R.P. (2001). Market potential for probiotics. American Journal of Clinical Nutrition, 73(2): 476-483.

Storhaug, C.L., Fosse, S.K., and Fadnes, L.T. (2017). Country, regional, and global estimates for lactose malabsorption in adults: a systematic review and meta-analysis. Lancet Gastroenterology Hepatology, 2(10): 738-746.

Swallow, D.M. (2003). Genetics of lactase persistence and lactose intolerance, Annual Review of Genetics, 37: 197-219.

Szakály, Z., Szente, V., Kövér, G., Polereczki, Z., and Szigeti, O. (2012). The influence of lifestyle on health behavior and preference for functional foods. Appetite, 58(1): 406-413.

Szakos, D., Ózsvári, L., and Kasza, Gy. (2020). Perception of older adults about health-related functionality of foods compared with other age groups. Sustainability, 12(7): 2748.

Varga, Zs., Román, M., and Tóth, Á. (2004). Production of lactose-free probiotic yoghurts for lactose sensitive people. Acta Alimentaria, 33: 377-385.

Verhagen, H., Vos, E., Francl, S., Heinonen, M., and van Loveren, H. (2010). Status of nutrition and health claims in Europe. Archives of Biochemistry and Biophysics, 501(1): 6-15.

Open Access. This is an open-access article distributed under the terms of the Creative Commons Attribution 4.0 International License (https://creativecommons.org/licenses/by/4.0/), which permits unrestricted use, distribution, and reproduction in any medium, provided the original author and source are credited, a link to the CC License is provided, and changes - if any - are indicated. (SID_1) 